\title{
Experiential factors in the enhancement of saccharin intake after shifts to water
}

\author{
KERMIT T. HOYENGA and KATHARINE BLICK HOYENGA \\ Western Ilinois University, Macomb, Illinois 61455
}

\begin{abstract}
The present experiment examined the enhancement of saccharin consumption observed after a temporary shift to water. An 8-day adaptation period of continuous access to saccharin was used. It was found that the avidity of albino rats for saccharin, as measured by daily consumption, can be increased significantly both by periods of saccharin deprivation and by social living conditions.
\end{abstract}

The so-called saccharin "elation" effect refers to an increase in saccharin consumption by nondeprived rats that is sometimes observed after a period of saccharin deprivation. The procedure typically involves several days of access to a $.25 \%(\mathrm{w} / \mathrm{w})$ saccharin solution presented for $1 \mathrm{~h}$ a day, both before and after a shift to tap water lasting from 1 to 5 days. However, this increase in saccharin intake relative to predeprivation baseline levels has not been a particularly reliable phenomenon. It was first demonstrated by Gandelman and Trowill in 1969 and was replicated later by Ashton, Gandelman, and Trowill (1970a); both of these studies used a 3-day shift to water to produce the elevated saccharin intake. DiLollo and Meyer (1970a) failed to find the effect after a 5-day shift, and Dube, Ashton, and Trowill (1970) found greater intake after a 1-day shift but not after a 3-day shift to water.

This variability in results is probably related to the complexity of the determinants of saccharin consumption. The saccharin intake prior to the shift to water was probably a complex function of both sensory affect ("good taste": Young, 1955; Sheffield \& Roby, 1950; Strouthes, 1971) and postingestive feedback (Le Magnen, 1971; Capretta, 1962). The intake is also probably affected by the learned shifts in the diurnal cycle of drinking as suggested by DiLollo and Meyer $(1970 a, b)$. Another factor that can affect the amount of saccharin consumed during limited access periods is living conditions, since Bauer and Angelo (1971) found that social living facilitated saccharin intake. It is unclear just which one of these aspects of saccharin consumption (if not all of them) would be most instrumental in the deprivation-induced enhancement of intake.

Thus, the present experiment attempted to extend the saccharin "elation" effect to conditions involving continuous access to saccharin both before and after the shift to water, with either social or isolated living conditions, in an attempt to find a more reliable procedure for producing the effect.

\section{METHOD}

Twenty 120-day-old Holtzman albino male rats, obtained from a commercial supplier, were placed in the wire-mesh cages; 10 were caged singly and 10 were paired. On each $24 \times 65 \times 18 \mathrm{~cm}$ cage were two symmetrically placed food hoppers, both always kept full of Purina rat chow. The ad lib water bottles were placed next to the right-hand side of the food hoppers. A bottle containing a $.16 \%$ saccharin solution (w/w), using tap water as solute, was placed on the left side of each cage for three periods during the experiment: Days 6-13, 20-26, and 34-38. (Of the solutions tested by Hammer, 1967, a .12\% solution was maximally consumed under ad lib conditions.) Each day the Ss, their water bottles, and their saccharin bottles (during the saccharin days) were weighed. The bottles were rinsed out and filled with fresh water or saccharin solution at least every 3 days.

\section{RESULTS}

The saccharin consumption data for Days 6, 20, and 34 (see Fig. 1) were subjected to a 3 by 2 analysis of variance. The grams drunk by the 10 isolated Ss were analyzed by randomly pairing two Ss and then using the sum as the analyzed score for that pair. Thus, the data subjected to the analysis of variance reflected five pairs

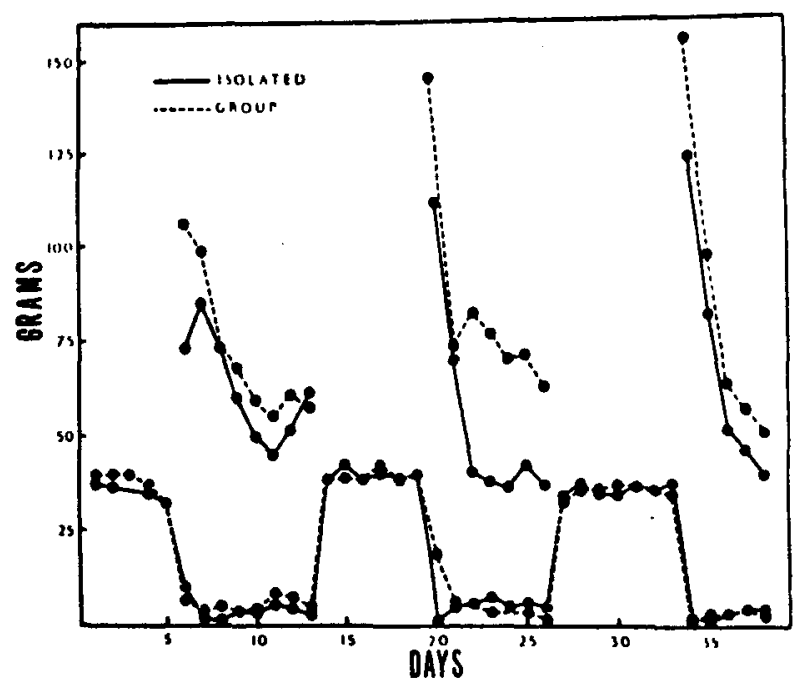

Fig. 1. The consumption of saccharin and water plotted as mean grams per $\mathbf{S}$ as a function of days for both the isolated and grouped animals. The two upper discontinuous lines represent saccharin consumption, while the lower two lines are for water consumption. 
of Ss under each of the two living conditions for each of the three "first" days of saccharin.

The effect of living conditions was significant $(F=7.3, \mathrm{df}=1 / 8, \mathrm{p}<.05)$, as was the effect of days $(\mathrm{F}=19.2, \mathrm{df}=2 / 16, \mathrm{p}<.01)$; the interaction did not even approach significance. The mean grams drunk for both groups for Days 6, 20, and 34 were 88.9, 12128.8 , and 136.8 , respectively. The mean grams drunk averaged over Days 6, 20, and 30 for the isolated group was 102.3, and the mean for the social group was 133.4 . Thus, this, in conjunction with Fig. 1, shows that a switch to water alone after several days of continuous experience with saccharin produced a level of saccharin intake significantly greater than any previously observed. Social living conditions also significantly increased the amount of saccharin drunk but had no effect on the magnitude of the elation effect.

The weight records kept on each animal indicated that there was no change in individual or group weights that could be attributed to either saccharin consumption or living conditions. From this and from the water consumption data in Fig. 1, it can be seen that the Ss probably adjusted to the voluntary fluid overload by increased urine output rather than by longer term changes in food or water intake. After saccharin was removed from their cages, readjustment to normal levels of fluid intake was essentially complete within the next day.

Figure 1 also shows the durability of the social facilitation of saccharin consumption. In fact, there is no consistent change in the magnitude of social facilitation over days. However, as can also be seen, living conditions had no effect upon water consumption.

\section{DISCUSSION}

The present experiment demonstrated reliable procedures for producing an increased intake of saccharin after a period of saccharin deprivation. The Trowill group referred to this increased intake as an elation effect, thus explaining the increased intake by classifying it with the other Crespi-type effects of elation and depression, or incentive contrast (a Feigl "low grade" explanation, 1954). Trowill and his colleagues also related the saccharin effect to behavioral contrast (Ashton, Gandelman, \& Trowill, 1970a). However, the relationship between the procedures used to produce the saccharin effect and the procedures used to produce these two types of contrast seems a bit obscure. Behavioral contrast refers to an increase in rate of response in one component of a schedule that usually occurs when the reinforcement density in another component is reduced, all within a given session (Terrace, 1971); it seems unlikely that behavioral contrast would be observed if the components of the schedule were separated by $24 \mathrm{~h}$, which is the case in the procedure used by Trowill to produce the saccharin effect. On the other hand, Crespi-type incentive contrast involves an increase in response rate produced by a change in the magnitude of the reward between sessions. However, not only has the "elation" effect been difficult to replicate (Kling \& Riggs, 1972), but also Crespi did not have to preexpose his Ss to the 16-pellet reward before a shift from 1 to 16 pellets would produce "elation." In the case of the procedures typically used to produce the saccharin effect, the increased intake of saccharin observed after the shift to water-alone conditions depends on the animal first having had initial experience with the larger magnitude reward before the shift from the smaller reward (water) to the larger magnitude reward (saccharin) will produce what was called "elation."

The differences between both the procedures and the results of the present study, when compared to those of the earlier saccharin experiments, raise other doubts as to the adequacy of the contrast explanation of the increased saccharin consumption. For example, Ashton, Gandelman, and Trowill (1970a) found that the increased intake of saccharin did not occur if, during the shift period, no bottles were placed in that position on the cage; there was also no saccharin effect seen if there was a shift to a period of daily presentations of empty bottles. In the present experiment, the increased saccharin intake occurred even though there were no bottles at all placed on the saccharin side of the cage at any time during the days of saccharin deprivation. If contrast were an appropriate explanation for the saccharin effect, it is not clear why an "unreinforced" drinking response would be required to produce the effect with 1-h/day procedures but not with continuous access procedures.

It is also not clear why continuous access to solutions would produce larger, more reliable, and more durable contrast (either incentive or behavioral) than would 1-h/day procedures. In the present study, the increased intake of saccharin was observed after shifts to water that lasted for 6 and 7 days. According to the results reported with the $1 \cdot \mathrm{h} /$ day procedure, the elevated saccharin drinking is only reliably observed after 1-day shifts to tap water, and 5-day shifts apparently will not produce the effect (Dube, Ashton, \& Trowill, 1970; DiLollo \& Meyer, 1970a). Also, the majority of the preceding studies compared postshift saccharin intake to the saccharin intake observed during the 3 days just prior to the shift to water. The present study compared postshift intakes to the greatest previously observed level, the first day of presentation of the saccharin solution. Inspection of the previously published figures shows that, in many of the previous studies, the postshift intake of saccharin might not have been significantly greater than the maximal preshift intake (but see Gandelman \& Trowill, 1969).

Another problem with the incentive explanation of the saccharin was pointed out by DiLollo and Meyer (1970b). They reported that they had found evidence for secondary reinforcing properties based on past 
association with a saccharin solution: More water was drunk from a bottle placed in the "saccharin" position on the cage than from another water bottle simultaneously presented. This reinforcing effect of prior association with saccharin had also been demonstrated by Sheffield and Roby (1950). An increased intake of water from a bottle associated with saccharin is, however, inconsistent with incentive contrast, since a contrast explanation of the saccharin effect would predict that a Crespi-type "depression" of intake would occur during the shift to the lower magnitude reward (the water bottle).

Perhaps a better approach to the phenomenon would be to refer to saccharin intake in this type of experiment as due to a positive affective arousal response to a sweet taste, similar to Young's theories (1955) of taste. In this case, the results from this and the earlier related experiments would seem to indicate that this positive affective response has learned as well as the innate components described by Young. The changes in intake observed both during the adaptation periods and as a consequence of the deprivation periods demonstrate that the positive affective response can be changed by experience. Furthermore, the apparent ability of stimuli to become secondary reinforcers when associated with saccharin would be predicted by this description of the saccharin effect. The mechanisms involved could be similar to the Hull-Spence $\mathbf{K}$ factor or to Cofer and Appley's anticipation invigoration mechanism (1964). Finally, according to this description of the saccharin effect, continuous access to saccharin prior to the deprivation period would be expected to produce a larger and more reliable effect than $1 \cdot \mathrm{h} /$ day procedures. In the latter case, the animals were "deprived" of saccharin for 23 out of every $24 \mathrm{~h}$ during the adaptation period, and further increases in that deprivation period would not be expected to have a great effect upon intake, since the typical deprivation-performance curves are negatively accelerated.

The social facilitation of saccharin intake observed in the present experiment is also consistent with the above description of the saccharin effect. Social facilitation of food or water intake is usually not observed under ad lib conditions (Hoyenga \& Aeschleman, 1969; Shelly, 1965; Bauer \& Angelo, 1971; the water consumption and weight gain data of the present experiment). Since social facilitation of saccharin was observed in the present experiment, it suggests that the response to saccharin is in some way similar to the response of a hungry animal to food.

However, before any more confidence can be placed in the existence of an experience-dependent positive affective response to tastes, it remains to be seen whether other consummatory behavior can also be changed by similar procedures. Ashton, Gandelman, and Trowill (1970b) and Ashton and Trowill (1970) attempted this for sucrose consumption, with only mixed success. Sinclair and Senter (1967), using procedures nearly identical to those of the present study, found that periods of deprivation enhanced alcohol intake. Also, the effects of varying lengths of adaptation and deprivation periods need to be investigated. But the present experiment did demonstrate that a strong, reliable increase in saccharin intake following a shift to conditions of water alone can be produced if the adaptation period to saccharin before the shift involved conditions of continuous access.

\section{REFERENCES}

Ashton, A. B., Gandelman, R., \& Trowill, J. A. Effect of food deprivation upon elation of saccharin drinking following a temporary shift to water. Psychonomic Science, 1970a, 21, 5-6.

Ashton, A. B., Gandelman, R., \& Trowill, J. A. Effect of reinforcement shifts upon subsequent sucrose consumption. Psychonomic Science, 1970b, 21, 7-8.

Ashton, A. B., \& Trowill, J. A. Effect of reinforcement shifts upon lick rate. Psychonomic Science, 1970, 21, 8-10.

Bauer, E. R., \& Angelo, W. L. Social isolation and saccharin consumption by the rat. Physiology \& Behavior, 1971, 7, 909-911.

Capretta, P. J. Saccharin consumption under varied conditions of hunger drive. Journal of Comparative \& Physiological Psychology, 1962, 55, 656-660.

Cofer, C. N., \& Appley, M. H. Motivation: Theory and research. New York: Wiley, 1964.

DiLollo, V., \& Meyer, P. N. Variations in fluid intake following shifts between water and saccharin solution. Psychonomic Science, 1970a, 18, 55-56.

DiLollo, V., \& Meyer, P. N. Pattern of daily water consumption in relation to intake of saccharin solution. Psychonomic Science, 1970b, 20, 265-266.

Dube, R., Ashton, A. B., \& Trowill, J. A. Responses to palatability shifts: Effects of varying the retention level. Psychonomic Science, 1970, 21, 10-12.

Feigl, H. Rejoinders and second thoughts in symposium on operationism. Psychological Review, 1945, 52, 284-288.

Gandelman, R., \& Trowill, J. S. Effects of reinforcement shifts upon subsequent saccharin consumption. Psychonomic Science, $1969,15,25$.

Hammer, H. R. Saccharin and sucrose intake in rats: Long- and short-term tests. Psychonomic Science, 1967, 8, 367-368.

Hoyenga, K. T., \& Aeschleman, S. Social facilitation of eating in the rat. Psychonomic Science, 1969, 14, 239-240.

Kling, J. W., \& Riggs, L. A. Woodward and Schlosberg's experimental psychology. Vol. 2: Learning, motivation, and memory. (3rd ed.) New York: Holt, Rinehart, \& Winston, 1972.

Le Magnen, J. Control and regulation of food intake. In E. Stellar and J. M. Sprague (Eds), Progress in physiological psychology. Vol. 4. New York: Academic Press, 1971.

Sheffield, F. D., \& Roby, T. B. Reward value of a non-nutritive sweet taste. Journal of Comparative \& Physiological Psychology, 1950, 43, 471-481.

Shelly, H. P. Eating behavior: Social facilitation or social inhibition. Psychonomic Science, 1965, 3, 521-522.

Sinclair, J. D., \& Senter, R. J. Increased preference for ethanol in rats following aicohol deprivation. Psychonomic Science, $1967,8,11-12$.

Strouthes, A. Thirst and saccharin preference in rats. Physiology \& Behavior, 1971, 6, 287-292.

Terrace, H. S. By-products of discrimination learning. In G. H. Bower (Ed.), The psychology of learning and motivation. Vol. 5. New York: Academic Press, 1972.

Young, P. T. The role of hedonic processes in motivation. In M. R. Jones (Ed.), Nebraska symposium on motivation. Lincoln: University Press, 1955

(Received for publication February 20, 1973; revision received June $4,1973$. ) 